\title{
Understanding the Incremental Impact of Built Environment on Climate Change of Metropolitan City Karachi
}

\author{
Nimra Kanwal ${ }^{1}$, Nuhzat Khan ${ }^{2}$ \\ RECEIVED ON 19.10.2018, ACCEPTED ON 03.05.2019
}

\begin{abstract}
Buildings are the most important part of development activities, consumed over one-thirds of the global energy. Household used the maximum energy around the world, likewise in Pakistan residential buildings consumed about half of total energy (45.9\% per year). The study aims to analyze the impact of building design on climate of Metropolitan City Karachi, Pakistan and to evaluate the change in urbanization patterns and energy consumption in the buildings. To have better understanding of the issues correlations was established amongst population, urbanization patterns, green area, number of buildings (residential and commercial), building design, energy consumption and metrological records (climate change parameters) by collecting the data from the respective departments. With the help of the collected data amount of carbon dioxide was estimated. The results reveled that during last 36 years the urban population of Karachi increased exponentially from $5,208,000$ (1981) to 14,737,257 (2017) with increase in urbanized area from $8.35 \mathrm{~km}^{2}(1946)$ to $3,640 \mathrm{~km}^{2}(2017)$ that may led to reduce the green area of the city from 495,000 hectors (1971) to 100,000 hectors (2015). Moreover, the building's design and numbers are being changed from 21 high-rise buildings (2009) to 344 (2017). It may be concluded that change in temperature pattern and climatic variability of the city may be due to increase in population and change in lifestyle that lead to high energy consumption that is prime source of increased in $\mathrm{CO}_{2}$ emission in the environment of Karachi city, However, Greenhouse Gases (GHG) releases are much lower than the levels reported from metropolitan cities around the world.
\end{abstract}

Keywords: Climate Change, Karachi, Pakistan, Urbanization, Energy Consumption, Building Trend, $\mathrm{CO}_{2}$ Emissions.

\section{INTRODUCTION}

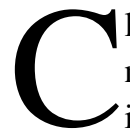
limate change is basically the alteration in the natural ecosystems which is directly or indirectly linked to the man-made activities that affects the world's atmosphere. The universal averaged surface temperature will rise from $1-3.5^{\circ} \mathrm{C}$ (about $2-6^{\circ} \mathrm{F}$ ) in the year 2100 as evaluated by the Intergovernmental Panel on Climate Change (IPCC) [1]. Climate change is the biggest consent globally because it is the greatest threat for mankind in the near future and its expected outcomes are the scarcity of water, natural resource depletion, increased energy consumption and it will also affect other socioeconomic regions like health, food production.

The industrial revolution is the source of increase in the GHG levels in the atmosphere which is responsible for the change in earth's temperature. These GHGs harmfully effect on the climate system and the lives of the people. Rising of global mean sea level, melting of snow and increase in the ocean temperature are the

\footnotetext{
${ }^{1}$ Institute of Business Management, Karachi, Pakistan. Email: kanwal.nimra@gmail.com (Corresponding Author)

${ }^{2}$ National Institute of Oceanography, Karachi, Pakistan. Email: nuzhatk@ gmail.com

This is an open access article published by Mehran University of Engineering and Technology, Jamshoro under CC BY 4.0 International License. 


\section{Understanding the Incremental Impact of Built Environment on Climate Change of Metropolitan City Karachi}

obvious changes because of the warming of the climate system [2]. The biggest worry is the contribution of the urban-based factors which are responsible for changing the global climate and also its impact on the urban cities themselves. Around 50\% of the total global population lives in the cities now and it is projected to increase by $75 \%$ in the year 2050 . Because of the increase in the urban population the phenomenon of the urban planning has changed drastically for designing, developing and sustaining urban cities [3]. Urban areas consume about $67-76 \%$ of total global energy and are responsible for $71-76 \%$ of fossil fuel-related $\mathrm{CO}_{2}$ emissions. The amount of $\mathrm{CO}_{2}$ emit by one household is 7.2 tons per year by electricity usage and an average person emits 18,000 $\mathrm{kg} \mathrm{CO}_{2}$ per year. And a single mature tree absorbs only $22 \mathrm{~kg} \mathrm{CO}_{2}$ per year [4].

Pakistan is the 6th largest nation in the globe with respect to the population size, having great extent of natural resources and a diversity of ecological areas. It is among 10 countries which are most affected by the climate change and the situation is getting worse. Pakistan's population increased from 32.5-180.7 million in 2012 after the independence in 1947 which is nearly $2.7 \%$ per year [5]. The increase in the urbanization of the cities in Pakistan is followed by the fast growing population. During the period of 19502012 the urban population of Pakistan is multiplied by more than ten folds and the total population increased over five-fold. The population of the major cities of Pakistan has also dramatically increased because of the urbanization trend, including Karachi. It is the metropolitan city of the country which has $20 \%$ of the total urban population. Every year the population of Karachi is increasing by $3 \%$, and according to projected trends this growth rate will continue in the next decade [6].

With economic development and increase in the population of people in the urban areas the land where it used to have one house with excess amount of ventilation and sun exposure is now shrinking to have vertically populated buildings with numerous amount of houses on the same area. The result is increase in the energy consumption in that area, the amount of energy which is consumed by one house hold on the same land is now multiply by the magnitude of hundreds. Energy consumption is increasing and no efforts are being taken to promote energy conservation [7].

Kugelman [8] concluded in his research that much of the urbanization of Pakistan is generated through migration. At the present time, rural Pakistanis are entering in the cities to outflow combat, ambiguity and natural disintegration, and moreover to set up new employment and improved necessary amenities.

The change in the climate of the world is irrefutable and these changes are the by-product of global GHG productions which is the result of man-made actions related to the burning of fossil fuel. To minimize the influence of GHGs, the construction industry has now taking steps for the energy efficient buildings. Though there are certain variations to the climate that cannot be ignored; these variations will have an important influence on the way buildings will function; and it will lean upon the accomplishment of global mitigation approaches. For the accommodation of the predicted changes we will have to bring variations in the way we plan, build, improve and reside in the buildings [9].

With the increase in the population of Karachi it is difficult for the urban centers to accommodate millions of people with in the limited area and it leads to the government to chop off trees and similarly to change the designs of the buildings. Buildings are the most important structures of the environment, the contribution of buildings, in the increase of energy consumption and resources depletion is increasing day by day, which is directly affecting the climate [10].

Buildings are responsible to use over one-thirds of the global energy; maximum usage of that energy is in houses and apartments. Energy consumption by the buildings in Pakistan is about half of the total energy consumed by the domestic region that is $45.9 \%$ yearly, while the industrial sector, use around $27.5 \%$. The energy used by China and UK is $25-30 \%$ and $40 \%$ for these purposes [11]. The optimum insulation thickness on external walls and roofs of the building was determined by the few scholars based on the peak cooling loads for an existing residential building in Lahore, Pakistan. Their results indicate that the optimum insulation thickness to reduce peak cooling 
loads up to $40.1 \%$ is 1 inch for external walls and roof respectively [12].

\section{MATERIALS AND METHOD}

The results and conclusions mainly depend upon the useful techniques which were adopted to accomplish the milestone of the research.

Area of Research: Karachi is the most populated and largest city of Pakistan and the capital of Sindh the land area of Karachi is $3,640 \mathrm{~km}^{2}$. The residential, commercial and Industrial area of Karachi is 7.7, 0.364 and $3.54 \%$ respectively. The total population of Karachi according to Pakistan Bureau of Statistics survey is 14.74 million in 2017 the average annual growth rate of change in population from 1998-2017 is $2.6 \%$ and the expected population till 2030 is 24.83 million [13]. Karachi was selected for the survey study because of the rapid urbanization and change in the climate.

Data Collection: The data of Population, Urbanization, Green Area, No of Buildings, energy consumption and climate change was collected through following methods.

The populated data of Karachi from 1941-2017 was collected from Pakistan Bureau of Statistics. $\mathrm{CO}_{2}$ emissions exhaled by humans was estimated by using Equation (1) [14]:

$\mathrm{CO}_{2}$ Emission $_{\mathrm{kg}}=0.9 \times 365 \times$ Population

Rate of CO2 Emission per person $=0.9 \mathrm{~kg} / \mathrm{day}$, Number of days in a year $=365$

The data of the energy consumption of residential and commercial buildings of Karachi was collected from K-Electric. $\mathrm{CO}_{2}$ emissions from the electricity was calculated from the Equation (2);

$\mathrm{CO}_{2}$ Emission $_{\mathrm{kg}}=0.537 \times$ Consumption $_{\mathrm{KWH}}$

Rate of CO2 Emission per $\mathrm{KWH}=0.537$

The data and information on the buildings and design was collected from Karachi Building Control Authority (KBCA). The data of the climate change of
Karachi was collected from Pakistan Metrological Department (MET).

Analysis Technique: The qualitative data analysis of the parameters including Population, Green Area, No. of Buildings, Energy consumption and climate change has been performed by using the Microsoft Excel 2013. The data of these parameters was graphically analyzed on excel to comprehend the results. The calculated $\mathrm{CO}_{2}$ emission from population and energy consumption was correlated with the climate change to deduce the results.

\section{RESULTS AND DISCUSSION}

Analysis of urbanization, building trends and energy consumption are important parameters used to explain climate change of the metropolitan city of Karachi.

Urbanization and Building Trend: Karachi has greatly affected by the rapid urbanization and in the increase in population growth during the last few years (Fig. 1) also shown in Table 1.

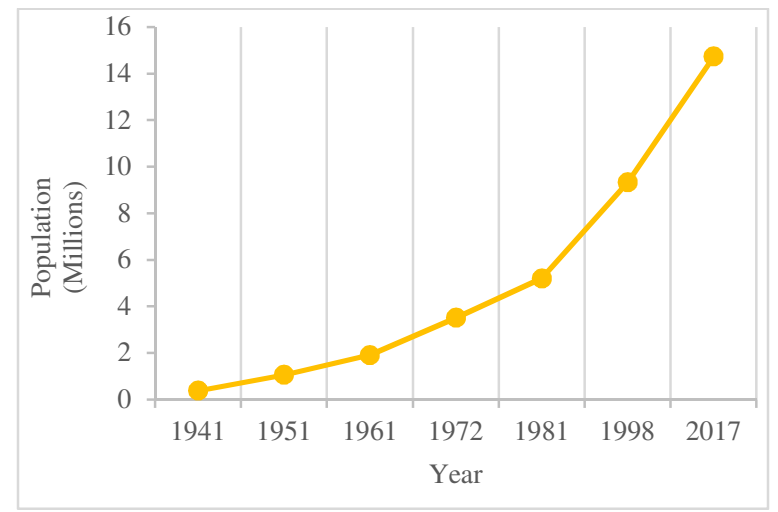

Fig. 1: Urban Population of Karachi (Source: Pakistann Beareau of Statistics)

\begin{tabular}{|c|c|}
\hline \multicolumn{2}{|c|}{$\begin{array}{c}\text { Table 1: Population of Karachi } \\
\text { (Source: Pakistan Beareau of Statistics) }\end{array}$} \\
\hline Year & Population (Millions) \\
\hline 1941 & 0.39 \\
\hline 1951 & 1.07 \\
\hline 1961 & 1.91 \\
\hline 1972 & 3.52 \\
\hline 1981 & 5.21 \\
\hline 1998 & 9.34 \\
\hline 2017 & 14.74 \\
\hline
\end{tabular}




\section{Understanding the Incremental Impact of Built Environment on Climate Change of Metropolitan City Karachi}

During the year 1941 the urban population of Karachi was 387,000 and it reached to 14.74 million in 2017. Fig. 1 and Fig. 2(a-f) shown before partition the urban population of Karachi was only 387,000 and urbanized area was $8.35 \mathrm{~km}^{2}$. With increases in population the urban sprawl of Karachi reached to $785 \mathrm{~km}^{2}$ in the year 2006. The change in urban sprawl since 1946-2016 is clearly demonstrated in the GIS maps (Fig. 2) of the city and also described in Table 2.

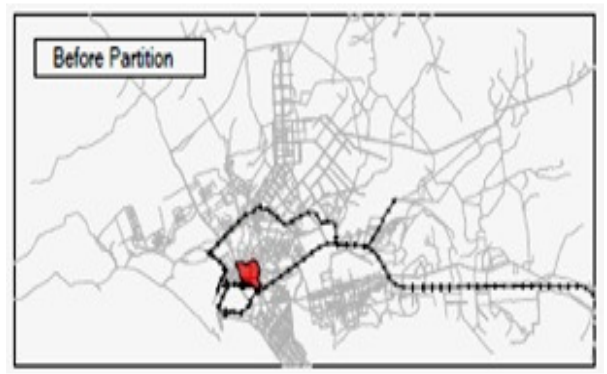

(a)

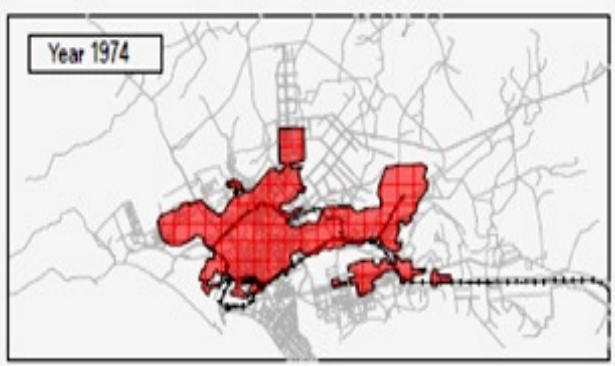

(c)

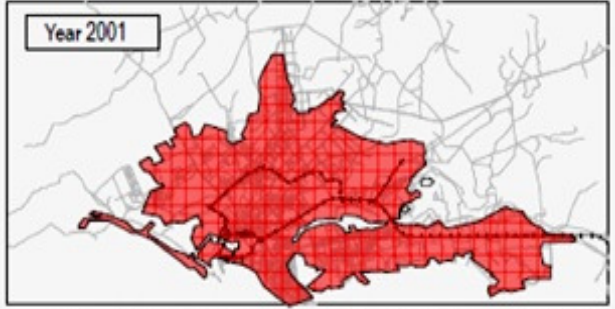

(e)
Around $409.63 \mathrm{~km}^{2}$ area has been urbanized during the years 1974-1997 and also during these years the population of Karachi increased by 5,824,000 which was the maximum increment in the population of Karachi after partition. Urbanization is the key factor for the development of a country but on the other hand it has its negative consequences as well including the chopping of trees (Table 3) for the development processes.

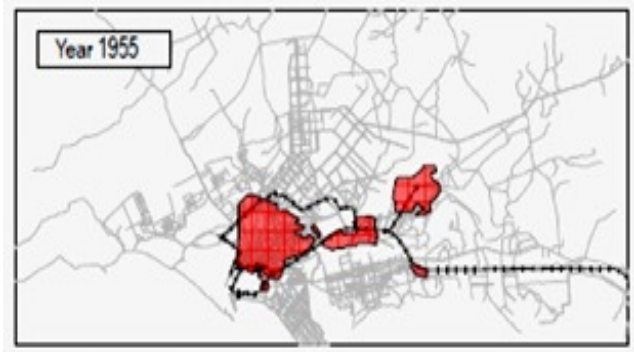

(b)

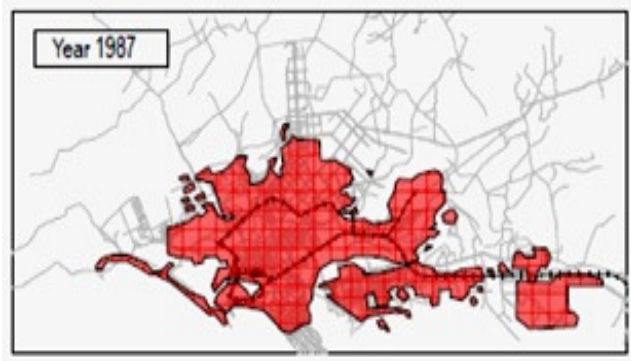

(d)

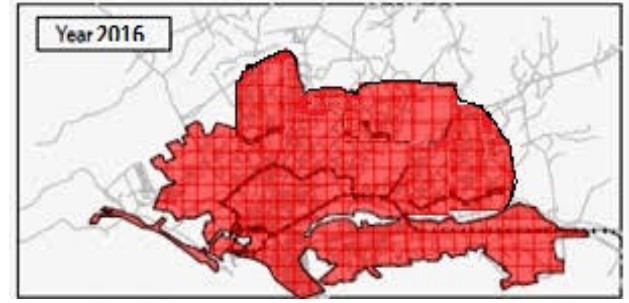

(f)

Fig. 2: Urbanization patterns of Karachi (Source: NIO)

\begin{tabular}{|c|c|c|}
\hline \multicolumn{3}{|c|}{ Table 2: Urbanization Area of Karachi (Source: NIO) } \\
\hline Year & Area $\left(\mathrm{km}^{2}\right)$ & $\begin{array}{c}\text { Area Change } \\
\left(\mathrm{km}^{2}\right)\end{array}$ \\
\hline 1946 & 8.35 & 0.00 \\
\hline 1955 & 104.26 & 95.91 \\
\hline 1974 & 286.3 & 182.04 \\
\hline 1997 & 695.93 & 409.63 \\
\hline 2001 & 726.15 & 30.22 \\
\hline 2006 & 785.45 & 59.33 \\
\hline
\end{tabular}

\begin{tabular}{|c|c|}
\hline \multicolumn{2}{|c|}{ Table 3: Change in Green Area of Karachi (Source: } \\
Forest Department of Sindh) \\
\hline Year & Area (000 Acres) \\
\hline 1970 & 495.00 \\
\hline 1975 & 410.00 \\
\hline 1980 & 320.00 \\
\hline 1985 & 270.00 \\
\hline 1990 & 235.00 \\
\hline 1995 & 210.00 \\
\hline 2000 & 180.00 \\
\hline 2005 & 140.00 \\
\hline 2010 & 110.00 \\
\hline 2015 & 100.00 \\
\hline
\end{tabular}




\section{Understanding the Incremental Impact of Built Environment on Climate Change of Metropolitan City Karachi}

In recent years, in Karachi, a large number of trees were chopped off (Fig. 3). Trees are the only natural source for the absorption of $\mathrm{CO}_{2}$ emission that are emitting from different sources. Among the 200 most polluted cities of the world, Pakistan's financial capital Karachi is ranked 14th. In 2016, around 1,200 trees have been chopped off for the construction of advertisement billboards near Shahrah-e-Faisal and Karsaz road. Moreover, in 2016 nearly 8,000 trees were chopped down for the Green Line Project but a single plant was not planted to replace the chopped tree. In 2017 Around 5,280 Full-Grown Neem Trees, planted along the Superhighway by the Sindh Forest Department, have been cut by contractors to widen space for the highway being constructed. Also in 2017 dozens of trees to clear way for the reconstruction of University Since the temperature will be increasing and oxygen can be less in amount in those places where trees are zapped completely. Cutting off trees means more emissions of $\mathrm{CO}_{2}$ in the air.

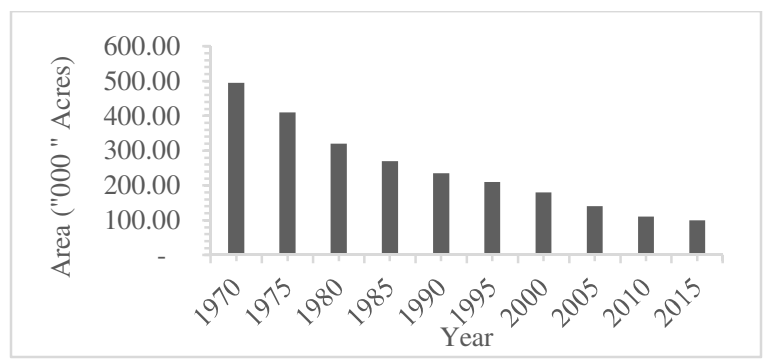

Fig. 3: Change in Green Area (Source: Forest Department of Sindh)

The areas from which the tress have been chopped off used for the infrastructure development which includes roads, bridges, industries, buildings, etc. The trend of high-rise buildings have been rapidly increasing day by day these years across Karachi (Fig. 4). Because of the rapid urbanization and increase in the population of the city, the land where it used to have one storied house, is converted in to high-rise building on the same land area.

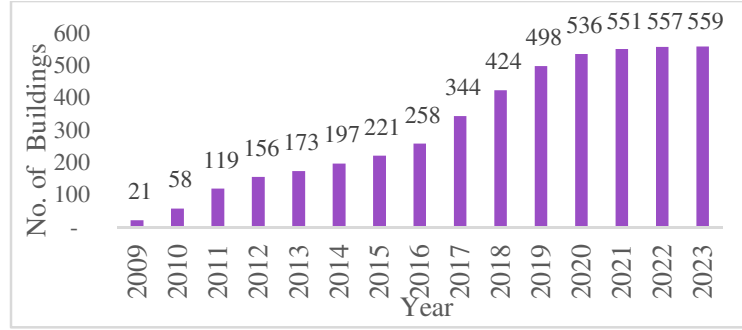

Fig. 4: High-Rise Building Trends (Source: KBCA)
Urbanization and Energy Consumption: With the increase in the vertical development energy consumption on the same land area is multiplied by several folds (Fig. 5) and it is the cause of increase in the emissions of carbon dioxide gas.

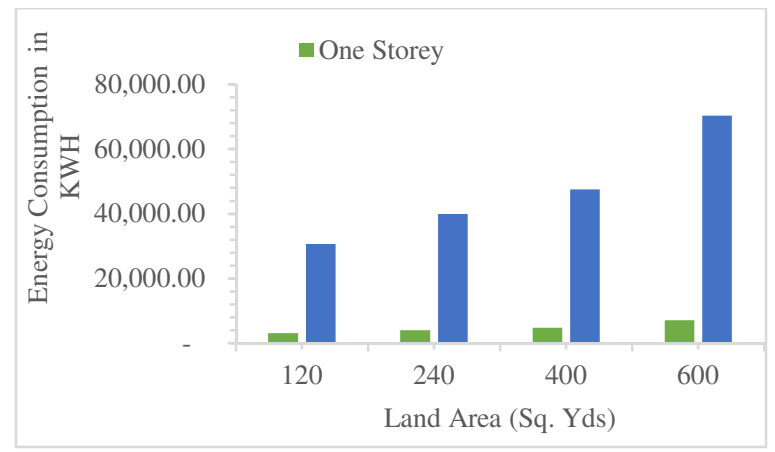

Fig. 5: Average Annual Energy Consumption of Residential Buildings (Source: K.E)

High-rise buildings are mostly being built along the main roads in the areas having the high commercial values including Gulistan-e-Johar, Gulshan-e-Iqbal, FB Area and commercial areas in DHA, the ground floor of these buildings are being replaced by the malls and offices and apartments above. In the newly commercialized areas the houses are being demolished and are replaced by the multi-storied buildings. The average annual consumption of commercial buildings is also mentioned in Table 4.

\begin{tabular}{|c|c|}
\hline \multicolumn{2}{|c|}{$\begin{array}{c}\text { Table 4: Average Annual Consumption of Commercial } \\
\text { Buildings (Source: K.E) }\end{array}$} \\
\hline Commercial Buildings & $\begin{array}{c}\text { Average Annual Consumption } \\
\text { MWH }\end{array}$ \\
\hline Private and Govt. Hospital & $8,615.97$ \\
\hline Hotel & $4,875.02$ \\
\hline Industry & $10,817.98$ \\
\hline Mall & $3,602.21$ \\
\hline Govt. School & 22.30 \\
\hline Private School & 336.91 \\
\hline Private University & $1,633.75$ \\
\hline Govt. University & 171.76 \\
\hline
\end{tabular}

Commercial buildings consumed more energy than residential buildings (Fig. 6). In some areas, the height limit for the construction of houses is ground plus one only, which is often ignored during the construction and the multiple floors are being added. This pattern is mainly observed in the areas such a as Gulistan-eJohar, North Nazimabad, Gulberg and New Karachi. These areas are undergoing speedy commercial growth. This will increase the load upon infrastructure. 


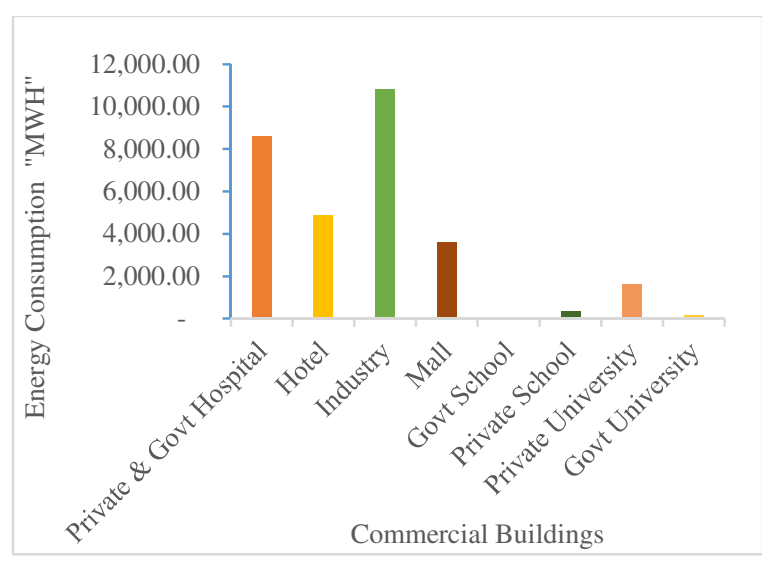

Fig. 6: Average Annual Energy Consumption of Commercial Buildings (Source: K.E)

Fig. 7 shows the annual total energy consumption of Karachi from buildings between the years 1991-2017. The energy consumption in 1991 was $3,472,800 \mathrm{KWH}$ which reaches to $13,894,200 \mathrm{KWH}$ after 25 years in 2017. From 1991-2001 the rate of consumption of energy was 0.54 that is around $54 \%$ of energy was consumed. However, from 2002-2011 the rate of consumption of energy was 0.72 that is $72 \%$ of energy was used in those years, $18 \%$ of increment in the energy usage. Similarly, from 2012-2017 the rate of consumption of energy is 0.80 that is $80 \%$ of energy consumed in the last five years. In the year 1991 the urban population was 7.3 million and the consumption was 3.4 MWH (Fig. 8) which was a big gap between the two. But because of rapid urbanization in the last 10 years this gap has filled and now energy consumption and population reaches to the same level. In 2017 the population was 14.7 million and energy consumed by this population was $13.89 \mathrm{MWH}$.

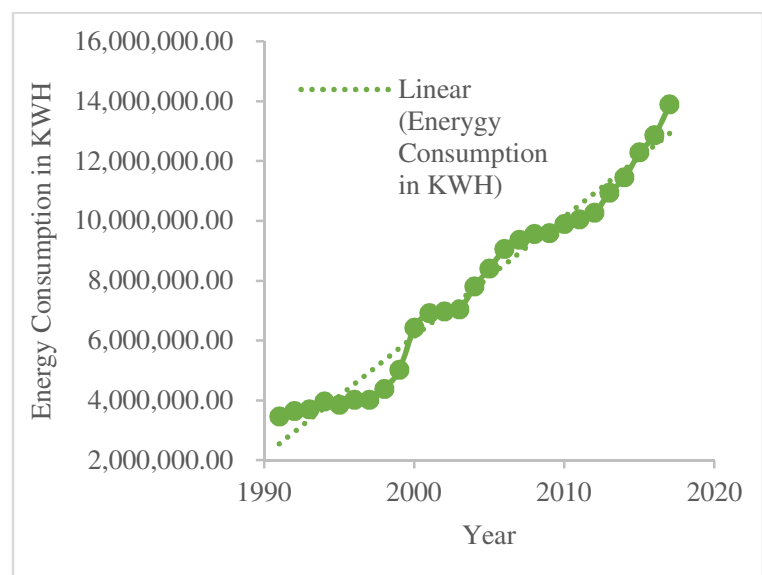

Fig. 7: Total Energy Consumption of Karachi (Source: K.E)

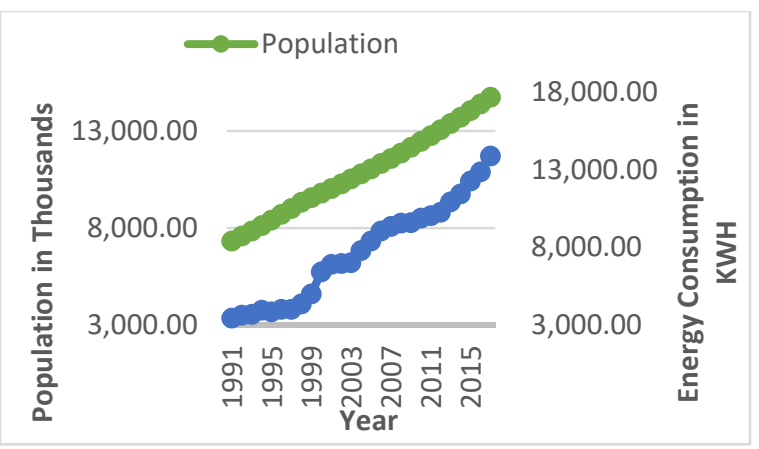

Fig. 8: Relationship of Population and Energy Consumption

Urbanization and Climate Change: The average annual climate of Karachi has been increased by $3{ }^{\circ} \mathrm{C}$ from the year 1948-2017 (Fig. 9). The highest average temperature was in the year 1999 because of the minimum amount of precipitation which has been shown in Fig. 10.

The temperature and precipitation has inverse relationship as shown in the Fig. 10. The highest temperature was recorded in the year in which the minimum amount of precipitation recorded.

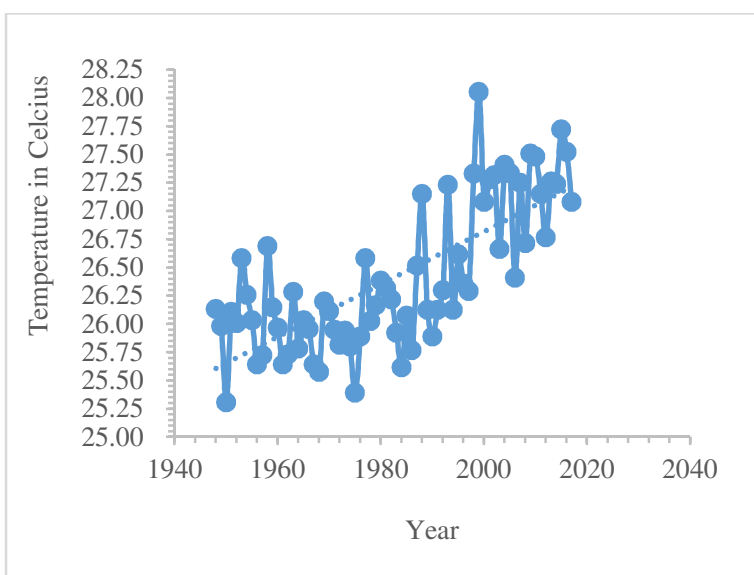

Fig. 9: Temperature Change of Karachi (Source: Met Department)

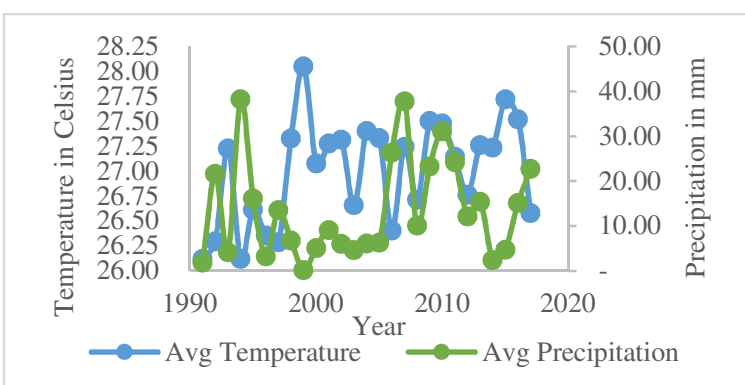

Fig. 10: Precipitation and Temperature of Karachi (Source: Met Department) 


\section{Understanding the Incremental Impact of Built Environment on Climate Change of Metropolitan City Karachi}

Human beings emit $\mathrm{CO}_{2}$ gas with every breath, more population means more emission of $\mathrm{CO}_{2}$ likewise more consumption of energy means more emission of $\mathrm{CO}_{2}$ gas, there is a direct relation between them (Fig. 11-12). Carbon dioxide from population and energy consumption has been calculated from Equation (1-2). The highest temperature recorded in the history of Karachi was $28.05^{\circ} \mathrm{C}$ which was in the year 1999 (Fig. 9). It means the highest increment in the urban area (Table 5), the highest increase in the population (Fig. 1) and the highest average temperature recorded were all occurred during the same years.

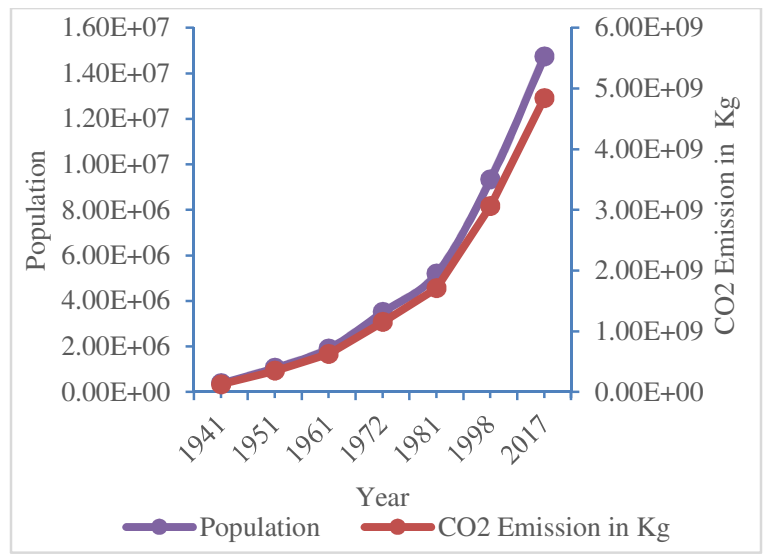

Fig. 11: $\mathrm{Co}_{2}$ Emission from Population

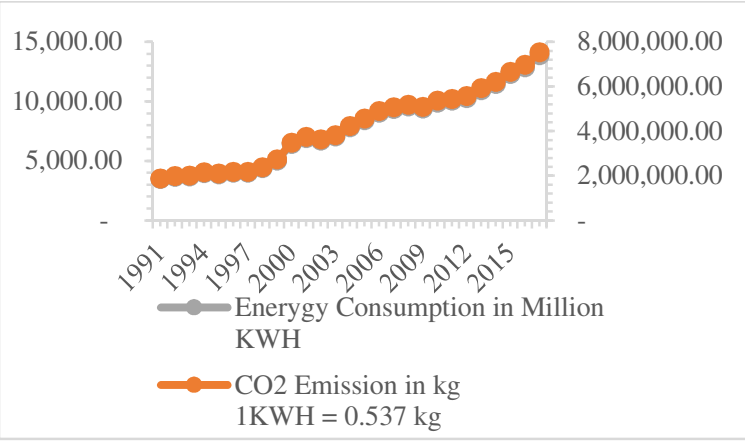

Fig. 12: $\mathrm{Co}_{2}$ Emission from Energy Consumption

\begin{tabular}{|c|c|c|}
\hline \multicolumn{3}{|c|}{ Table 5: Average Temperature and $\mathrm{Co}_{2}$ Emissions } \\
\hline Year & Average Temperature & $\mathrm{CO}_{2}$ Emission in Ton \\
\hline 1961 & 25.64 & $6.28 \mathrm{E}+08$ \\
\hline 1972 & 25.82 & $1.15 \mathrm{E}+09$ \\
\hline 1981 & 26.32 & $1.71 \mathrm{E}+09$ \\
\hline 1998 & 27.33 & $3.07 \mathrm{E}+09$ \\
\hline 2017 & 26.58 & $4.84 \mathrm{E}+09$ \\
\hline
\end{tabular}

The correlation between the average temperature and $\mathrm{CO}_{2}$ emissions of Karachi from the year 1961-2017 has been shown in Fig. 13. In the year 2017 the average temperature decreased because climatic variability doesn't only depend upon the emissions of $\mathrm{CO}_{2}$ but it also effected by the other climatic events such as increase in the amount of precipitation (Fig. 10). $\mathrm{CO}_{2}$ emissions increases in the same way the number of buildings increase and energy consumption respectively. The more $\mathrm{CO}_{2}$ emission in the air from both population and energy consumption the more it triggers the climate of the city Karachi. Urbanization has a three-fold impact on the climate from the increase in the population and the number of buildings, to the chopping off trees and the increase in energy consumption, all of these activities are responsible for the change in the climate.

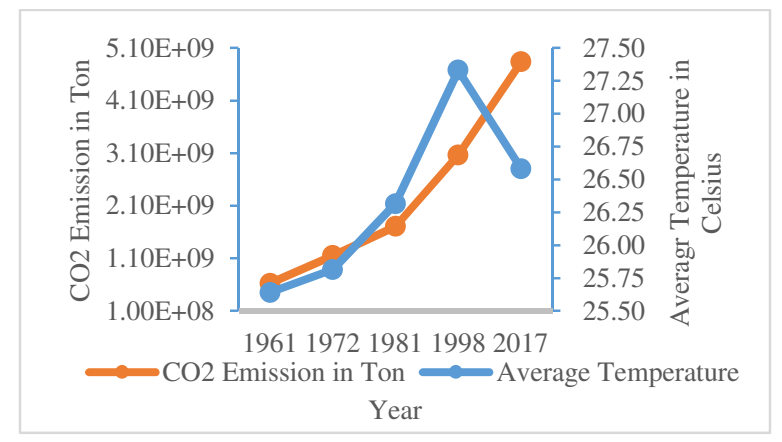

Fig. 13: Average Temperature and $\mathrm{Co}_{2}$ Emission

\section{CONCLUSION}

The present research work focuses on the effect of urbanization and energy consumption on the climate change of Karachi. For this purpose, various parameters namely, population, green area, urbanization pattern and energy consumption patterns has been analyzed and it is concluded that increase in the population and urbanization has a direct relation. It is also concluded that change in structural design specially the vertical development contributes more in the $\mathrm{CO}_{2}$ emissions rather than horizontal development. The green area from the city of lights Karachi has been vanishing day by day which increase the concentration of carbon emissions in the atmosphere. As per the analysis the carbon dioxide emits by the human is more than the energy consumption.

It is further concluded that change in temperature pattern of the city since 1948-2017 and climatic variability may be due to increase in population and lifestyle of the city that has relatively increased the $\mathrm{CO}_{2}$ levels in the environment of Karachi. The

Mehran University Research Journal of Engineering and Technology, Vol. 39, No. 4, October 2020 [p-ISSN: 0254-7821, e-ISSN: 2413-7219] 
government should focus on the illegal immigration, use of recyclable materials and implement the restrictions of multi-storied buildings in residential areas, and introduce campaign to create awareness amongst the people about the significance of tree plantation. According to WHO regional office for Europe, in every urban city there should be at least 0.5 1 hectare green space within 300 meters linear distance which is around 5 minutes' walk from home [16].

\section{ACKNOWLEDGEMENT}

The authors are grateful to the Institute of Business Management, Shaheed Zulfiqar Ali Bhutto Institute of Science \& Technology, Karachi Electric, National Institute of Oceanography, Dawood University of Engineering \& Technology, Karachi, Pakistan, for support and encouragement.

\section{REFERENCES}

[1] IPCC, "Mitigation of Climate Change", Contribution of Working Group-III to the Fourth Assessment Report of the Intergovernmental Panel on Climate Change, 2007.

[2] IPCC, "Fourth Assessment Report (AR4)", Intergovernmental Panel on Climate Change, pp. 8-10, 2007.

[3] United Nations, World Urbanization Prospects, Vol. 12, 2005.

[4] Güneralp, B., Zhou, Y., Urge-Vorsatz, D., Gupta, M., Yu, S., Patel, P.L., Fragkias, M., Li, Z., and Seto, K.C., "Global Scenarios of Urban Density and Its Impacts on Building Energy Use through 2050", National Academy of Sciences, 2017.

[5] UNEP, "The Environment and Climate Change Outlook of Pakistan", 2011.

[6] Altaf, A., Khan, M., Shah, S.R., Fatima, K., Tunio, S.A.,m Hussain, M., Khan, M.A., Shaikh, M.A., and Arshad, M.H., "Sociodemographic Pattern of Depression in Urban Settlement of Karachi, Pakistan", Journal of Clincal Diagnostic Research, Vol. 9, No. 6, pp. 9-13, 2015.

[7] Sohail, A., and Qureshi, M., "EnergyEfficient Buildings in Pakistan", A Science Journal of COMSATS - Science Vision, Vol. 16, pp. 27-38, December, 2011.

[8] Kugelman, M., "Urbanisation in Pakistan: Causes and Consequences", Noref, January,
2013.

[9] Gething, B., "Design for Future Climate", Technology Stragey Board, April, 2010.

[10] Meinshausen, M., Smith, S.J., Calvin, K.V., and Daniel, J.S., "The RCP Greenhouse Gas Concentrations and their Extensions from 1765-2300", Climate Change, Vol. 109, No. 1, pp. 213-241, 2011.

[11] Zhang, F., Cooke, P., and Studies, A., "Green Buildings and Energy Efficiency”, Center for Advanced Studies, Cardiff University, No. 2, pp. 1-28, 2013.

[12] Siddique, S., Arif, S., and Khan, A., "Optimum Insulation Thickness for Walls and Roofs for ReducingPeak Cooling Loads in Residential Buildings in Lahore", Mehran University Research Journal of Engineering and Technology, Vol. 35, No. 4, pp. 523-532, Jamshoro, Pakistan, October, 2016.

[13] United Nations, "The World's Cities in 2016", Economic Society Conference pp. 29, 2016.

[14] Micpohling, "How Much $\mathrm{CO}_{2}$ Emitted by Human on Earth Annually?", [Online]. Available:

https://micpohling.wordpress.com/2007/03/2 7/math-how-much-co2-is-emitted-by-

human-on-earth-annually/. [Accessed: 15Apr-2018].

[15] Energy, C., "How to Calculate Your CO2 Emissions", [Online]. Available: https://www.coronaenergy.co.uk/how-tocalculate-co2-emissions/. [Accessed: 17Apr-2018].

[16] WHO Regional Office for Europe, "Urban green spaces: a brief for action”, 2017. 